\title{
The Sorcerer's Apprentices
}

\section{Les apprentis sorciers}

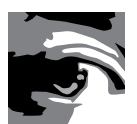

ROBERT G. EVANS

\begin{abstract}
Riding concerns about physician shortages, Canadian medical schools have expanded their annual enrolment by $80 \%$ over the last 13 years. Including rapid growth in net immigration, the annual "crop" has nearly doubled. (Population has grown by about $14 \%$.) The physician workforce is just now showing the impact - a $6 \%$ increase in physicians per capita in the last three years. In the last decade, medical expenditure per physician has also risen, by nearly 35\% above general inflation. The drivers are rapidly increasing diagnostic testing and imaging, and the growth of alternative payment programs. More doctors, combined with growing expenditure per doctor, will have serious cost implications. What benefits are we buying?
\end{abstract}

\section{Résumé}

Face aux préoccupations en termes de pénuries de médecins, les écoles de médecine du Canada ont augmenté de 80 pour cent leurs admissions annuelles au cours des 13 dernières années. En tenant compte de la croissance rapide de l'immigration nette, la « récolte annuelle » a presque doublé. (La croissance de la population a été d'environ 14 pour cent.) On commence à peine à en voir l'impact dans la main-d'œuvre médicale - une croissance de 6 pour cent de médecin par habitant pour les trois dernières années. Au cours des dix dernières années, les dépenses par médecin ont également augmenté de près de 35 pour cent au-dessus du taux 
d'inflation. Les inducteurs font augmenter rapidement les tests de diagnostic et l'imagerie, ainsi que l'apparition d'autres modes de paiements. La présence de plus de médecins, conjuguée à la croissance des dépenses par médecin, aura de sérieuses répercussions en termes de coûts. Quels avantages en tirons-nous?

A NOTHER FALL, ANOTHER ENTERING CLASS OF BRIGHT AND ENTHUSIASTIC MEDICAL students. They will undoubtedly be the largest class ever. The admirably compendious Canadian Medical Education Statistics (AFMC 2010) reports that first-year enrolment has increased every year since 1997/98. The 2010/11 entering class numbering 2,829 was fully $80 \%$ larger than the 1,577 who entered 13 years earlier.

This is a remarkable expansion, a sustained average growth of $4.6 \%$ per year. Net inmigration adds about 700 more per year, well over twice the number in 1997/98, so the total growth in the annual crop is closer to $90 \%$. The Canadian population, over the same period, has increased about $14 \%$ - about $1 \%$ per year. There are a lot more doctors now in the pipeline! Yet, calls for further expansion continue.

Figure 1 shows the annual number of physicians graduating from Canadian medical schools since 1941, augmenting the AFMC data with estimates by Judek (1964) for the Hall Commission (Canada 1964). ${ }^{1}$ It then plots a crude estimate of the net annual number of new graduates on the assumption that physicians practise for 40 years and then abruptly stop. (A further assumption is that no new places are opened for a quarter-century after 2010/11.) The figure also includes data on net immigration.

FIGURE 1. Graduates of Canadian medical schools, |94|-20II, hypothetical net additions and net migration

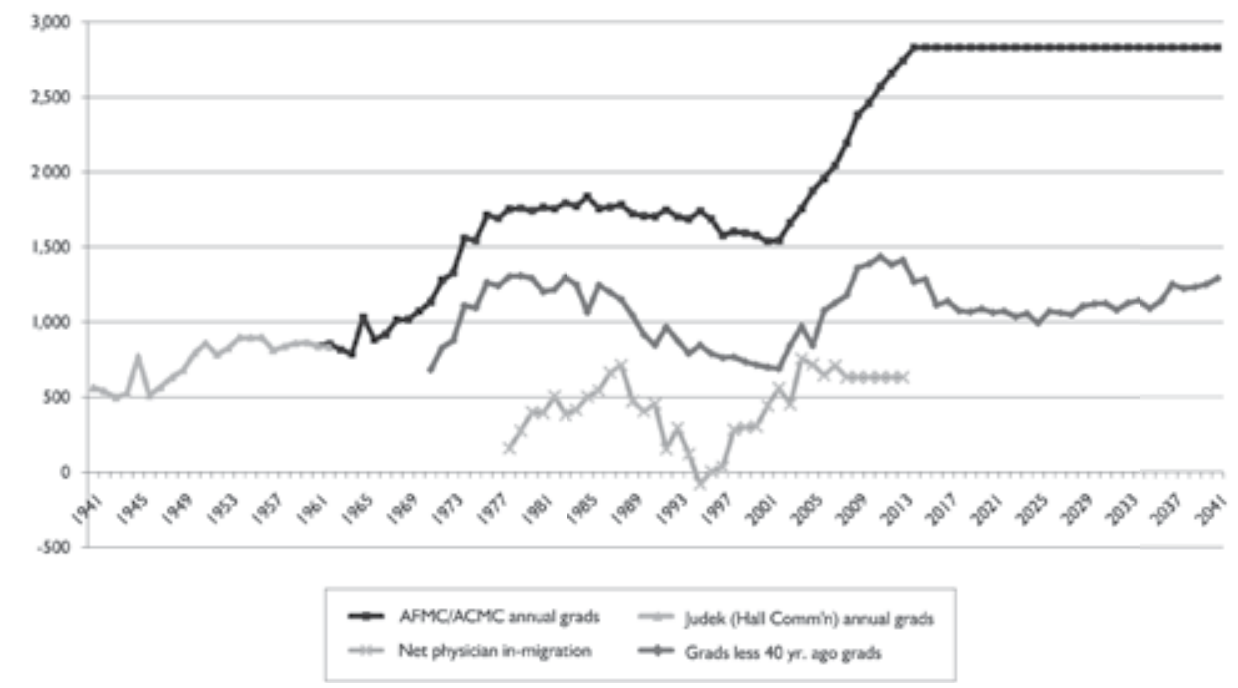


Two things stand out. First, medical school capacity has not expanded smoothly in line with population growth - far from it. Medical schools have grown in two large bursts, one in the late 1960s/early 1970s and one from the late 1990s to the present. And second, these bursts of expansion have very long-term effects, spanning decades. This year's entering class will graduate in four years, finish residency several years later and then be in the workforce for decades. The long-term impacts of medical school expansion take a very long time to work through.

Unrealistic as it is, the assumption of a uniform 40-year working life for physicians shows that the entrants during the first wave of expansion have become, 40 years on, the retirees of the present. Much of the current wave of expansion simply replaces those of the first wave.

Each of these waves of expansion responded to widespread perceptions of a looming "physician shortage." How accurate were those perceptions? In the case of the first wave, they rested on assumptions that were simply wrong, and by a wide margin. Medical schools were built to serve people who never arrived.

The Hall Commission, reporting in 1964, projected physician requirements on the assumption that the post-war "baby boom" would continue. They further anticipated that the introduction of universal public medical care insurance would trigger an exodus of doctors to the United States and a surge in patient demand for care. Consequently, Hall recommended a major expansion in medical school capacity. This was done (Figure 1).

Neither the physician exodus nor the surge in demand actually materialized. But the major flaw was in the population projections. No one could have anticipated it, but between 1964 and 1966 the baby boom suddenly ended. The Great Obstetrical Contraction reduced the annual number of births in Canada by about one-third. As a result, the Hall Commission population projections were by 1991 nearly 10 million too high. The expansions that Hall thought necessary to maintain his recommended ratio of 850 people per physician instead set off an unintended increase in supply that continued for the next 20 years.

Internal Health Canada papers show that by the early 1970s, policy makers understood what was happening. In February 1975, the federal government acted to choke off physician immigration, initiating a 20 -year struggle with would-be immigrant physicians. But efforts to cut back on domestic production were unsuccessful, fought off by medical school representatives. A series of medical workforce studies were carried out using methodologies structured so as to be incapable of identifying a physician surplus (Lomas et al. 1985). In the end, physician-to-population ratios just kept rising until population growth finally caught up with the class sizes set 20 years earlier.

That was then, this is now. But the important messages from "then" are twofold. First, it is politically extremely difficult, almost impossible, to cut back on medical school places once they have been opened. ${ }^{2}$ Despite provincial government concerns about rising supply (and costs), the number of places in Canada remained effectively unchanged in the 20 years from the mid-1970s to the mid-1990s. And second, an essentially accidental major increase in physician supply per capita, from 1970 to 1990, did not result in underemployed physicians. Utilization of physicians' services adapted to the increased supply. Whether the additional 
physicians were "needed," and what impact their activities might have had on the health of Canadians, are good and debatable questions, but essentially irrelevant after the schools were built or expanded. Once trained, physicians find work.

We may therefore anticipate that the new capacity now put in place is irreversible. As in the case of the previous major expansion, the impact on the total supply of physicians will unfold slowly, but relentlessly, over decades. And the newly trained physicians produced or imported will all be busy - and paid.

This impact is now emerging. Last December, the Canadian Institute for Health Information (2010a) reported that there were approximately 68,100 active physicians in Canada, 2,700 more than in the previous year. The increase of $4.1 \%$, the largest increase since 1988, follows increases of $2.2 \%$ and $2.8 \%$ in 2007 and 2008, respectively. Physician supply has risen nearly $10 \%$, or about $6 \%$ per capita, in just three years. But that is only the beginning.

Figure 2 plots the number of physicians per capita in Canada back to 1968, showing the long rise that followed the previous burst of new training places. The ratio was stable from the late 1980s to the early 2000s, but began to rise again in 2005, about seven years after the beginning of the current wave of expansion in training places. The increase appears to be accelerating; for better or for worse, we have now entered another long period of growth in physician supply.

FIGURE 2. Canada, physicians per 10,000 population, 1968-2009

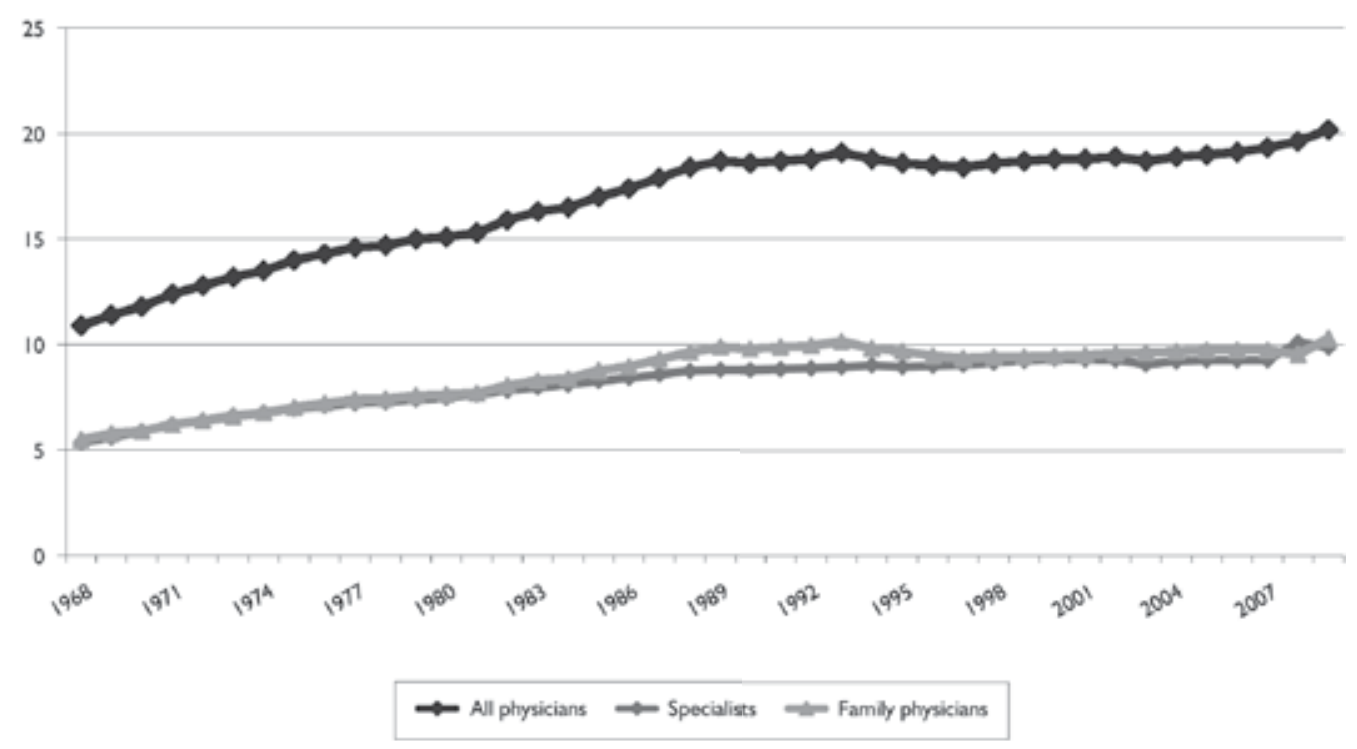

But surely this is a good thing? This time, everyone agrees that there is a physician shortage, right? Certainly, many people report difficulty finding a doctor. The $\mathrm{CBC}$, in a rather vapid story on the release of the 2009 physician numbers, gave prominence to the comments of Dr. Rob Boulay, president of the College of Family Physicians of Canada: "It's always good 
news when we're graduating more physicians and when we have more physicians in our workforce' [because as] the number of family doctors increases, health outcomes improve" (CBC 2010). How many physicians do we need? More!

The standard arguments are trotted out - the aging population, the falling average hours of work by younger physicians (all those women!) - arguments that advocates for expansion have been using for at least 30 years. And, of course, the Canadian population is aging: all else being equal (which it never is), this should increase the need for physicians.

But as is well known, the impact of aging is slow and, in any one year, very small - about $0.5 \%$ per capita. References to a "grey tsunami" and a "tidal wave of chronic illness" are simply ignorant - or deliberately mendacious. They are, however, great propaganda - as H.L Mencken said, "neat, plausible, and wrong" - and very effective in distracting attention from the real cost drivers in the health system.

The "elephant in the living room," however, is revealed by the second standard argument. Younger physician cohorts put in, on average, fewer hours of clinical work than their predecessors. But if so, why are average expenditures per physician not falling? They have been rising, and rising quite rapidly, particularly over the past decade.

Table 1 shows the increase in average expenditures per capita on health services and major components between 1999 and 2009, as reported by the Canadian Institute for Health Information (2010b) and adjusted for general inflation rates. Whatever other shortages the Canadian health services have faced, there has been no shortage of money!

TABLE 1. Canadian health spending, percentage increase per capita, inflation-adjusted

\begin{tabular}{|l|c|c|c|}
\hline & $\mathbf{1 9 9 9 - 2 0 0 4}$ & $\mathbf{2 0 0 4 - 2 0 0 9}$ & I999-2009 \\
\hline Hospitals & 19.1 & 11.7 & 33.0 \\
\hline Physicians & 16.4 & 24.4 & 44.8 \\
\hline Rx drugs & 46.1 & 19.0 & 73.7 \\
\hline Total health & 22.2 & 16.5 & 42.3 \\
\hline Provincial governments & 21.2 & 17.7 & 42.6 \\
\hline
\end{tabular}

Increased expenditures for physicians' services - or indeed, any other services - reflect some combination of increasing volumes of output and increasing prices (sector-specific inflation). Expenditure equals quantity times price; there is no third factor. More services are being provided, the prices paid for them are outpacing inflation, or there is a combination of both. To the extent that volumes of services are increasing rapidly, how is that consistent with a "shortage" of physicians (and a need for more)? Canadians are receiving more and more services every year, regardless of the physician supply. But to the extent that these expenditure increases do not reflect steadily increasing output per physician, then the prices of physicians' services must be increasing quite rapidly, well beyond general inflation rates. Why? 
Either way, increases flow back into provider incomes - where else could they go? If per capita medical expenditures, inflation-adjusted, have risen by $44.8 \%$ over the decade, and physicians per capita have increased by $7.8 \%$, then expenditures per physician have increased by $34.3 \%$, or $2.99 \%$ per year. ${ }^{4}$

Persistent increases of $3 \%$ in both physicians per capita and expenditure per physician would obviously imply per capita expenditures rising over $6 \%$ annually, plus general inflation. Figure 1 suggests that the 2,700 additional physicians in 2009 may be unusual; annual increments of 1,700 to 2,000 (net of retirements) may be more typical, if training places and net immigration are not further increased. And the 2010 physician expenditure forecasts indicate some slowing - but not much. The numbers still imply unacceptable rates of cost escalation. Where is all the money going, and what is it buying?

Evans and McGrail (2008) pointed to this central question. ${ }^{5}$ Subsequent research in British Columbia (McGrail et al. 2011) has provided some partial answers. There are two parts to the story. Medical Services Plan expenditures flow to physicians through two principal channels: fee-for-service payments and alternative payment programs (APPs).

Fee-for-service payments are still the primary source of public payments. But increases in fees did not outpace general inflation. To the contrary - over the period 1996/97 to 2005/06, fee increases added only $11.5 \%$ to total expenditures, while the consumer price index for British Columbia rose by $20.4 \%$. The average volume of services provided per capita, however, increased by $14.2 \%$, or $1.5 \%$ per year. So why does the widespread perception of shortage not moderate?

The explanation may lie in trends in the types and recipients of the particular services provided. Over the nine-year period, there were very large increases in the per capita volume of diagnostic services - imaging and laboratory tests. Adjusting for fee changes, per capita expenditures on these rose by $28.4 \%$ and $42.1 \%$, respectively. These increases were much greater among the older age groups $-59.4 \%$ and $64.4 \%$, respectively, for those over 75 . But general and family practice services per capita for those under 50 - the majority of the population - actually fell. This decline occurred despite a small increase in the number of general and family physicians per capita, perhaps reflecting declining hours of work.

These findings suggest a plausible reconciliation of perceptions of physician shortage, with escalating expenditures. At least in British Columbia, money has been poured into reimbursing diagnostic services for the elderly and very elderly, but access to primary care for the non-elderly appears to have been constrained. Increasing the supply of physicians may address the latter issue but not the former. Indeed, insofar as more recently trained physicians tend to be more reliant on the ever-expanding arsenal of diagnostic technology, overall expenditures per physician will continue to rise as their numbers grow.

Does all this increased diagnostic activity among the very elderly actually generate health benefits? That is a much larger question, but as this is written the Globe and Mail is reporting the findings of the United States Preventive Services Task Force, with respect to the widely used and promoted prostate-specific antigen (PSA) blood test for prostate cancer: 
Those PSA blood tests that check for prostate cancer do more harm than good and healthy men should no longer receive them as part of routine cancer screening.... The recommendations ... will not be a surprise to cancer specialists. ... No major medical group recommends routine PSAs ... . Yet, the vast majority of men over 50 have had at least one PSA blood test. (Neergaard 2011)

Note that this is not a question of cost-effectiveness. The test, when routinely ordered for healthy men of any age, actually does harm. The high false-positive rate triggers further interventions, including surgery, that have serious side effects. At the very least, therefore, the fact that a diagnostic intervention is recommended by a physician and accepted by a patient is not a priori evidence of benefit.

Runaway diagnostic testing rates, particularly of the elderly, are not the whole story. Fee-forservice payments have shrunk, over the years, from roughly $95 \%$ of total expenditures on medical services in British Columbia to about $75 \%$, with the difference made up of various forms of APPs. (Trends are similar across Canada.) Some of these correspond to actual provision of clinical services; others offer incentive or benefit payments with no specific service quid pro quo.

Increases in payments, with no increase in service volumes, are simply de facto price increases: more is being paid out, in total, for the same volume of services. When these latter can be identified and factored into the overall increase in service prices - added to explicit fee increases - the total price of physicians' services rises significantly more rapidly than a simple index of physicians' fees.

But the APPs that support the provision of clinical services present a more intractable measurement problem. The BC Ministry of Health does not keep track of the nature and volumes of services provided by such programs. One can only "guesstimate" (aka perform sensitivity analysis) to factor expenditure increases into changes in prices and changes in quantities. Some work has been done, suggesting that these programs, though they certainly add to total service output, are also a significant additional source of de facto price increase. After all, fee-for-service reimbursement has been both praised and condemned for encouraging high volumes of service output. ${ }^{6}$ But the findings are not yet in a fit state to release. One can say confidently, however, that a lot of money is going out the door and no one has a clear picture of what it is buying.

The question of Canadian physician supply is now moot. The new doctors are on their way, and whether or not we will need them all is no longer relevant. It may be that as cost containment efforts begin to bite we will again see renewed limits on the inflow of foreign-trained physicians, but we will not be able to turn down the domestic taps as supply increases.

Cost containment policy must therefore be focused on trying to limit the growth in expenditures per physician. In principle, this approach has great potential. As noted above, between 1999 and 2009 Canadian expenditure per physician, inflation-adjusted, grew 34.3\%. If growth had been held to the general inflation rate, expenditures in 2009 would have been $\$ 18.3$ billion 
rather than the reported actual of $\$ 24.6$ billion. That would still have been an increase of $47 \%$ over the decade, about $4 \%$ per year to cover both inflation and the increase in physician supply.

The targets, then, are twofold. Growth in diagnostic testing has to be brought under control, both in how ordering decisions are made and in how tests are paid for. Including laboratory procedures in fee schedules as if they were medical acts is absurd; this has been understood for decades.

And second, a lid must be placed on APP program payments. Funding for benefit and incentive programs should be folded into the negotiation of fee schedules, recognizing that they are, like fees, simply part of the average prices physicians receive for their services. The "black boxes," those APPs that do provide clinical services, should be opened up to show what services they actually provide, and to whom. If they are in fact providing services commensurate with their cost, why, as Chan (2002) put it, does it feel like a shortage?

Even if the growth in expenditures per physician can be reined in, the coming increases in numbers have, once again, foreclosed for decades the possibilities for exploiting the full competence of complementary and substitute health personnel, expanding interprofessional team practice and in general, shifting the mix. It will also be difficult, and expensive, for ministries of health to reallocate resources away from "doctors, drugs and hospitals" to long-term and home care, and the care of complex chronic conditions. While others talked, Canada's medical schools have acted. The money is pre-committed.

\section{NOTES}

${ }^{1}$ Figure 1 displays numbers of graduates, lagging by four years the numbers of entrants quoted above. Entry to independent practice requires a further two or more years of residency training, depending upon specialty choice. The figure assumes no increase in enrolment after 2010/11; we already know that is too low.

${ }^{2}$ The small reductions of the early 1990 s were soon reversed.

${ }^{3}$ In fairness, there were more thoughtful medical comments quoted, concerning the difficulties of defining an ideal supply. Physician requirements depend upon the context of practice, the availability of other personnel and equipment and other factors, and the inadequacy of simple "doc-pop" ratios has long been generally recognized. But these considerations turn out, in practice, to be irrelevant. Whatever factors go into the mix, the same answer comes out - train more doctors (see also Lomas et al. 1985). And simple doc-pop ratios do at least show one thing - trends in the numbers of income claimants.

${ }^{4}$ It does not follow that physicians are all going home with wheelbarrows full of money. Others, individuals and corporations, are also involved in the provision of medical services; physicians direct as well as provide. But every dollar is being paid to someone - the money is not being sent to Mars.

${ }^{5}$ Celebrants of medical school expansion, however, have resolutely refused to connect the dots. As increased physician numbers begin to feed into further expenditure increases, we will no doubt hear more distracting nonsense about the "grey tsunami." Anything to avoid addressing the central question: Where is all the money going?

${ }^{6}$ If that is so, why would anyone in his or her right mind want to shift away from fee-for-service reimbursement in a system allegedly suffering from a physician shortage? Would one not want to encourage a high volume of service output per physician? That anomaly, however, raises the thorny question of the relationship between physicians' activities and health outcomes under different modes of reimbursement. Much better to stick to the tried and true mantra: more doctors equals more services equals better health. Everyone knows that "it ain't necessarily so," but no one wants to deal with the implications. 


\section{REFERENCES}

Association of Faculties of Medicine of Canada (AFMC). 2010. Canadian Medical Education Statistics (32nd ed.). Ottawa: Author.

Canada. 1964. Report of the Royal Commission on Health Services (Hall Commission). Ottawa: Queen's Printer.

Canadian Broadcasting Corporation. 2010 (December 3). “Supply of Doctors Jumps: Report.” Retrieved October 13, 2011. <http://www.cbc.ca/news/health/story/2010/12/02/doctor-supply-canada.html>.

Canadian Institute for Health Information (CIHI). 2010a."Supply, Distribution and Migration of Canadian Physicians." Ottawa: Author.

Canadian Institute for Health Information (CIHI). 2010b. "National Health Expenditure Trends, 1975 to 2010." Ottawa: Author.

Chan, B.T.B. 2002. From Perceived Surplus to Perceived Shortage: What Happened to Canada's Physician Workforce in the 1990s? Ottawa: Canadian Institute for Health Information.

Evans, R.G. and K.M. McGrail. 2008. "Richard III, Barer-Stoddart and the Daughter of Time." Commentary. Healthcare Policy 3(3): 18-28.

Judek, S. 1964. Medical Manpower in Canada. Study prepared for the Royal Commission on Health Services. Ottawa: Queen's Printer.

Lomas, J., M.L. Barer and G.L. Stoddart. 1985. Physician Manpower Planning: Lessons from the Macdonald Report. Ontario Economic Council Discussion Paper Series. Toronto: Ontario Economic Council.

McGrail, K.M., R.G. Evans, M.L. Barer, K.J. Kerluke and R. McKendry. 2011. “Diagnosing Senescence:

Contributions to Physician Expenditure Increases in British Columbia, 1996/97 to 2005/06." Healthcare Policy 7(1): 41-54.

Neergaard, L. 2011 (October 7). “Common Prostate Cancer Test 'Doesn't Work': U.S. Panel.” The Globe and Mail. Retrieved October 13, 2011. <http://www.theglobeandmail.com/life/health/new-health/health-news/commonprostate-cancer-test-doesnt-work-us-panel/article2194225/>. 